\title{
INMIGRANTES SENEGALESES, ISLAM Y COFRADÍAS *
}

\author{
JOAN LACOMBA \\ Universidad de Valencia
}

PALABRAS CLAVE ADICIONALES

Religión, Identidad, Inserción social, Migraciones, España.

\section{ADDITIONAL KEYWORDS}

Religion, Identity, Social Insertion, Migrations, Spain.

\begin{abstract}
RESUMEN. Este artículo recoge parte de los resultados de una investigación sobre los inmigrantes musulmanes en Valencia y sus estrategias de adaptación en un medio mayoritariamente no musulmán. De entre las diferentes nacionalidades estudiadas en ese trabajo los ciudadanos senegaleses constituyen el grupo que ofrece mayores elementos de interés para su análisis. En concreto, a su particular entendimiento del Islam, los inmigrantes senegaleses añaden al mismo formas de organización inexistentes en otros colectivos musulmanes. El sistema de cofradías, de gran peso en su sociedad de origen, es importado por los propios inmigrantes a la sociedad de acogida. En el nuevo contexto migratorio la organización cofrádica se convierte en un instrumento fundamental de regulación de la comunidad y de inserción social y laboral para los inmigrantes musulmanes senegaleses.
\end{abstract}

ABSTRACT. This article presents a portion of the results of a study on Muslim immigrants in Spain and their strategies of adaptation in a non-Muslim environment. Out of the groups of different nationalities studied, the Senegalese present the most original adaptative strategies. Aside from their particular interpretation of Islam, they have put into place organisational forms unlike those found in other groups of Muslims studied. They have brought to Spain the system of confraternities whose influence is very strong in their society of origin. In the new context, this organisation into confraternities has become a fundamental instrument in regulating the community and in the social

\footnotetext{
"Una versión anterior de este artículo fue publicada en francés por la Revue Européenne des Migrations Internationales (2000), vol. 16, $\mathrm{n}^{\circ} 3$, pp. 85-103.

E-mail: joan.lacomba@uv.es
}

\section{Revista Internacional de Sociología (RIS)}

Tercera Época, nº 29, Mayo-Agosto, 2001, pp. 163-187. 
integration of Senegalese Muslim immigrants.

La inmigración musulmana senegalesa ofrece una serie de características que la convierten en un terreno privilegiado para el estudio de la relación existente entre la dimensión identitaria religiosa y las estrategias de inserción en el ámbito migratorio'. Con ese objetivo nos referiremos, de entrada, a las particularidades religiosas de los inmigrantes musulmanes senegaleses a la hora entender y poner en práctica el Islam, que les distinguen netamente del resto de inmigrantes musulmanes de otras procedencias ${ }^{2}$. Como afirma el investigador senegalés Mustafá Diop, como "minoría dentro de otra minoría, los musulmanes negroafricanos, sobre todo los senegaleses, ofrecen trazos bien específicos en cuanto a sus instituciones religiosas y a sus prácticas" (Diop, 1990: 78). También analizaremos el carácter comunitario de la inmigración senegalesa y la fuerza de la solidaridad que la acompaña. Éste es otro rasgo que les distingue de la mayor parte de los otros colectivos inmigrantes musulmanes, pues como señala Bruno Etienne, "las minorías culturales y de culto, con algunas excepciones, no constituyen prácticamente ni etnias, ni comunidades, salvo dos excepciones: los turcos y los murids senegaleses, que se organizan en comunidades autónomas" (Etienne, 1987: 299).

Estas características diferenciales son reconocidas también por los propios inmigrantes senegaleses entrevistados ${ }^{3} \mathrm{y}$, de forma genérica, marcan una distinción respecto a los inmigrantes musulmanes procedentes de países árabes.

\footnotetext{
'El texto de este artículo ofrece los principales resultados relativos al colectivo senegalés asentado en la ciudad de Valencia, estudiado dentro de una investigación de tesis doctoral más amplia sobre la inmigración musulmana en su conjunto, que originalmente se tituló "El juego entre la exclusión y la inserción. Modificación y permanencia de la identidad cultural entre los inmigrantes musulmanes". Posteriormente ha sido publicada en su mayor parte dentro del libro "El Islam inmigrado. Transformaciones y adaptaciones de las prácticas culturales y religiosas", editado en el 2001 por el Ministerio de Educación, Cultura y Deportes.

${ }^{2}$ La comunidad senegalesa en España constituye una minoría dentro del colectivo inmigrante musulmán (marroquí en su mayor parte). Tomando cifras oficiales, tras el proceso de regularización del año 2000, la Delegación del Gobierno para la Extranjería y la Inmigración cifró en 10.848 el número total de inmigrantes senegaleses en situación regular. Estimando en un $20 \%$ el porcentaje de inmigrantes senegaleses que podrían hallarse en situación irregular, ello nos daría una cifra aproximada de 13.000 personas, de las que alrededor de una décima parte residirian en la ciudad de Valencia y su área urbana. El resto de los inmigrantes senegaleses en España se concentran en los núcleos urbanos de Madrid, Barcelona, Sevilla y Alicante.

${ }^{3} \mathrm{La}$ investigación se apoya en una metodología eminentemente cualitativa, que empleó como técnica básica la entrevista en profundidad. En total se entrevistó a treinta y dos inmigrantes musulmanes, de los cuales cinco eran hombres senegaleses de diferentes etnias, edades y niveles de formación. Los fragmentos de entrevistas que aparecen en el artículo corresponden a esos cinco informantes.
} 
Pero el sistema de cofradias y las vinculaciones que generan conllevan una serie de creencias y prácticas que no siempre son admitidas por la ortodoxia del Islam institucional en inmigración. De hecho, en ocasiones se consideran incluso como ajenas a la propia religión musulmana ${ }^{4}$. No obstante, su conocimiento resulta imprescindible para comprender las variables que operan en la configuración de las dinámicas y procesos que condicionan las estrategias de inserción de los inmigrantes senegaleses en las sociedades de acogida.

\section{LAS COFRADÍAS EN EL ISLAM SENEGALÉS}

Las cofradías (tariqa en el singular árabe) pueden ser definidas originalmente como las órdenes místicas o hermandades aparecidas en el universo islámico, a partir del siglo XI, para facilitar el acercamiento entre los creyentes y la divinidad. Sin embargo, a pesar del uso que haremos del término cristiano "cofradía" para referirnos a estas asociaciones con fines religiosos, entre ambas formas de organización existen diferencias de fondo. Las manifestaciones de sociabilidad de estos dos tipos de instituciones (procesiones, peregrinaciones, romerías, ferias, fiestas, banquetes, espectáculos, juegos, deportes, asistencia mutua) tienen muchos puntos en común, pero las metas espirituales son diferentes. Gilles Veinstein afirma que, a diferencia de las tariqas ${ }^{5}$ musulmanas, "las cofradías cristianas no están dirigidas a la unión con Dios, no son místicas. Su razón de ser es la búsqueda de la salvación, una salvación más individual que colectiva, pero que se busca colectivamente, lo cual corresponde al principio asociativo de la cofradía y a la solidaridad que une a sus miembros" (Veinstein, 1997: 29).

De acuerdo con Felice Dassetto ${ }^{6}$, en el contexto musulmán el término

\footnotetext{
${ }^{4}$ Uno de los informantes senegaleses entrevistado en el proceso de investigación nos decía: "puede haber diferencias por ejemplo en lo que se llaman los talismanes. Los árabes por ejemplo dicen que eso es como una especie de profanación y para el negro africano el talismán es solamente una forma de protegerse, de tener suerte, porque aquí se puede ver por ejemplo muchos que acuden a hechiceros o videntes para el mal de ojo o esas cosas. En la religión cristiana creo que eso no está prohibido, es una forma de proceder para protegerse".

${ }^{5}$ Emplearemos una forma castellanizada del plural (tariqas) de amplia aceptación, en lugar de la fórmula ortodoxa turuq en árabe.

${ }^{6}$ Felice Dassetto ha sido pionero en el estudio del fenómeno de las cofradías y otras formas de religiosidad no ortodoxas entre la población inmigrante musulmana en Bélgica, como el caso de la extensión del movimiento Tabligh entre los marroquíes. Puede consultarse al respecto Dassetto (1988). En el caso del Estado español la influencia del Tabligh puede rastrearse en Beatriz Aguer (1991).
} 
RIS

REVISTA INTERNACIONAL DE SOCIOLOGIA

№ 29, Mayo - Agosto, 2001

JOAN LACOMBA

cofradia se utiliza para designar las formas de asociación religiosa que se caracterizan por una organización, una creencia y un ritual específicos. La tariqa (en su traducción literal "vía" o "método") es una respuesta particularmente fértil para una minoría en busca de una forma de religiosidad vuelta hacia la meditación y la práctica ascética (Dassetto, 1984: 114).

La mayor parte de estudiosos coinciden en que las cofradías se sitúan en la frontera del Islam ortodoxo. Por ello, el culto de los santos, la obediencia al guía espiritual y la inserción en la práctica mística de elementos no islámicos, característicos de las cofradías, se han revelado útiles instrumentos para instalar el Islam sobre otras tradiciones culturales. Así se han podido recrear interesantes formas de sincretismo religioso, en la superposición del Islam a los cultos locales pre-islámicos, sobre todo en el caso del África Sub-sahariana. Una buena muestra es el caso de la cofradía murid en Senegal, algunos de cuyos miembros entrevistados en el proceso de investigación han tratado de relatar las diferencias entre ambas tradiciones, al tiempo que éstas son minimizadas en favor de una referencia común al Islam:

"De entenderlo a lo mejor hay diferencias, pero la práctica es la misma. Entenderlo, bueno, sabes que es una religión importada. El Islam es una religión que vino de fuera, porque los almorávides árabes son los que llevaron el Islam e intentaron convertir a muchos africanos al Islam. Entonces la gente que aprende el Islam, que lo conoce cuando es pequeño, no se puede comparar con los que la religión nació en su medio, pero la práctica es la misma. Solamente que hay ciertas diferencias, por ejemplo como se puede encontrar en otras religiones como lo que se dice en el cristianismo y el catolicismo o los protestantes, pero solamente se notará una ligera diferencia".

El fenómeno de las cofradías en el África Occidental y Central es fruto de la presencia y del desarrollo del misticismo sufi en África del Norte. Ampliamente presente en el Magreb, y sobre todo en Marruecos (en donde el marabutismo o culto a los santos es una forma de religiosidad particularmente extendida), es de esta región de donde proviene la islamización de las zonas sudanesas, entre las cuales se encuentra Senegal (Copans, 1980: 164).

Las cofradías disponen, como centro organizativo, de las zagüias ${ }^{7}$, que han venido actuando tradicionalmente como importantes polos culturales, pero que con el tiempo también han llegado a convertirse en centros de poder político

\footnotetext{
${ }^{7}$ Las zagüías son centros religiosos que suelen estar situados al lado de la tumba de un santo local y contar con habitaciones para peregrinos y místicos. También pueden disponer en ocasiones de una biblioteca y otras instalaciones.
} 
y económico, además de espiritual. En su evolución, las cofradías se han dotado de sistemas de organización y de un universo identitario y simbólico propio, hasta convertirse en la actualidad en importantes instrumentos de socialización.

En principio, la meta principal de una cofradía - tal como escribe Veinsteines "conservar, transmitir y difundir la enseñanza mística del fundador, como un modo de acceder a Dios, a través de determinados ritos, prácticas, ejercicios y conocimientos esotéricos" (Veinstein, 1997: 18). Pero junto a su dimensión espiritual, las cofradías también pueden tener una dimensión terrenal, que se concreta en la posesión de un patrimonio material (tierras, edificios, dinero...) y de un patrimonio simbólico. Ello les proporciona, en diferentes grados, una capacidad de influencia y presión en los medios sociales, políticos y económicos que no hay que subestimar.

En este sentido, el mismo Venstein afirma que "un antropólogo dirá que, en estas circunstancias, el jeque (el cheij o cabeza de la cofradía) convierte un capital simbólico acumulado sobre bases de la cofradía, en capital político. Pero aunque el jeque no ocupe el vértice del Estado, algo que suele ser excepcional, le quedan muchas maneras de intervenir en la vida política de su país, de apoyar al poder o luchar contra él, poniendo su influencia personal o movilizando a sus discípulos, electores y/o agitadores potenciales (...) La vida política contemporánea de países como Egipto, Indonesia, Sudán, Pakistán, Senegal e incluso la Turquía post-kemalista no se entiende bien si no tenemos en cuenta el factor cofradías" (Venstein, 1997: 25).

En Senegal el peso religioso, social, económico y político de las cofradías es reconocido por la práctica totalidad de los investigadores que se han aproximado al complejo mapa etno-lingüístico y religioso de este país. En efecto, el Islam en su lectura cofrádica constituye la cultura de pertenencia de una parte importante de la población senegalesa. Se calcula que, en 1989 , el $94 \%$ de la población de Senegal era de religión musulmana y que más de tres cuartas partes de la misma pertenecían a alguna de las tres cofradías mayoritarias (un $49 \%$ a la cofradía tiyaniya, un $33 \%$ a la muridiya y un $12 \%$ a la qadiriya). Además, existen otras cofradías menores, como la de los layen (Schmidt, 1994: 11).

La cofradía tiyaniya es una de las más importantes órdenes místicas musulmanas en África del Norte y del Oeste. Explica Gilles Kepel que "fue fundada en 1789 por Ahmed El Tiyani, nacido hacia 1737 en la población marroquí de Ain Madi, y persigue garantizar a sus adeptos la salud en el más allá, estableciendo entre ellos un cierto número de relaciones y redes sociales de solidaridad. Los tiyan se distinguen de otros musulmanes en general, y de otros grupos místicos o sufies en particular, por el cumplimiento de un cierto número de ritos que les son propios - sobre todo la recitación de letanías y oraciones específicas. Si la rama argelina de la cofradía ha sido uno de los más firmes sostenes de la colonización francesa en ese país, en África del Oeste ha 
constituido uno de los instrumentos más vigorosos de la islamización de las poblaciones animistas, y está particularmente bien implantada entre los soninkés, que forman el grueso de la inmigración musulmana africana en Francia" (Kepel, 1987: 130).

Uno de nuestros entrevistados senegaleses (de etnia fulbé o fulani), nos relataba del siguiente modo el origen y características propias de la cofradía tiyaniya, así como algunas de las diferencias respecto a la cofradía qadiriya:

\footnotetext{
"Ahmed Cheij Tiyani transformó la religión en otra manera. El birdu es cuando terminan de rezar en la mezquita y se sientan y se quedan allí a rezar otras muchas suras. La tariqa tiyani el birdu que tiene es un rosario de bolas, y hacen cien veces para una sola sura. Cuando terminas de hacer las prácticas de las cinco oraciones del día tienes que hacer cien veces. El origen de Cheij Tiyani es argelino, pero cuando ha tenido problemas con la política se fue a Marruecos y luego se ha instalado en Senegal. Los religiosos de la etnia fulbé que han tenido contacto con él han cogido la tariqa suya. Hay otra tariqa que se llama qadiriya. Los qádir vienen de Abdel Qádir Yilani también. Es lo que hacen los tiyani, pero tienen otra forma cuando lo aplican en las mezquitas. Por ejemplo, los tiyani tienen que hacer cien veces, pero los qádir aplican ciento uno".
}

Por su parte, la cofradía qadiriya tiene su origen en la persona de Abdel Qádir Yilani, nacido en 1165 en Irán, y es una de las más extendidas en el mundo musulmán. Su fundador se caracterizó por la fidelidad al Corán y las tradiciones del Profeta, así como la ortodoxia de su método místico. Sin embargo, con posterioridad la qadiriya ha adoptado nuevos desarrollos y prácticas cuestionables desde el punto de vista de la pureza de sus orígenes. Por ejemplo, tras su entrada en Senegal en el siglo XVIII, la qadiriya dio lugar a finales del XIX a una nueva cofradía exclusivamente senegalesa: la muridiya, fundada por Amadou Bamba.

Dice Jean-Louis Triaud que Bamba "nunca pretendió crear una cofradía distinta. La nueva identidad se formó por sí misma en unas condiciones históricas especiales. Fue perseguido y deportado por los franceses (1895-1907), luego se reconcilió con ellos y fundó un imperio religioso, verdadero Estado dentro del Estado, cuya prosperidad y la garantía colonial se basaban en el cultivo del cacahuete por los talibé (discípulos). La muridiya tomó el relevo a los Estados wolof desmantelados por la conquista colonial, y se presentó como intermediaria entre la población y el poder francés" (Triaud, 1997: 524).

Frente al carácter muchas veces elitista de la qadiriya y la tiyaniya, la cofradía murid ha sabido conectar con los sectores populares, tanto de la población rural como urbana, hasta el punto de convertirse en la más dinámica de las cofradías actuales en Senegal y la que ha experimentado un mayor crecimiento en los úitimos años.

Ciertamente, en el caso senegalés, el Islam de las cofradías ha tenido una 
de sus expresiones más exitosas en el movimiento murid, fundado en la época colonial por el cheij Amadou Bamba. Convertido en fuerza de resistencia al dominio francés, en la biografia de Bamba se entremezclan los hechos históricos con las referencias a sus poderes sobrenaturales. Por ejemplo, el discurso de uno de los entrevistados nos muestra cómo se articulan ambas dimensiones en los relatos sobre su figura:

\begin{abstract}
"Sid Ahmed Bamba no tiene bolsillos nunca. Tampoco hay fotos de él. La última vez dice la gente que había los franceses y le hacen fotos y todo eso, pero no sale nada. Un día llama a sus miembros y les dice: os voy a dar una foto para que me vea todo el mundo en la puerta del cementerio. Todos los murid van a ir a la puerta del cementerio. Y le hacen una foto y ya está. No hay dos ni tres. Sólo una foto. Hasta ahora no hay. Los franceses lo cogen y él sólo quería leer los libros del Corán, quiere estar en un sitio libre que no hay nadie. Siempre está leyendo y leyendo. Al final la gente viene a estudiar con él. Lee los textos con sus compañeros. Se fue a la selva solo. Y cuando regresa de la selva empieza a contarlo todo sin leerlo. Al final todo el mundo vuelve a estudiar con él. Pero si está siempre con la gente no tiene tiempo para hablar y para hacer cosas de Dios. Por eso se fue a un sitio donde no hay nada de gente y se esconde. La gente le sigue buscando hasta que le encuentran y llegan allí y estaba sentado debajo de un árbol, con una tribu que se llama peul, porque ellos viven en la selva con su ganado. Y dicen: yo he visto a Sid Ahmed Bamba aquí. Cuando llegan allí todo el mundo se sienta y dice: quitad esos árboles $y$ limpiad esas pajas para hacer un sitio para rezar. Y coge una madera y hace así (dibujando en el suelo) y dice: esta es la mezquita. Donde está la mezquita de Tuba antes no había nada, pero ahora hay siete kilómetros de cada lado".
\end{abstract}

El vigor y fuerza social del muridismo son reconocidos incluso por los miembros de otras cofradías senegalesas. Es el caso de un miembro de la cofradía qadiriya, quien, a la capacidad de organización de los murid, suma su influencia sobre acontecimientos centrales para el conjunto de los musulmanes, como el comienzo del mes de Ramadán:

\footnotetext{
"Hay diferencias. Los murid tú dices equis y ellos dicen $y$, por ejemplo. Ellos siguen a Ahmed Bamba, es su protector, ellos tienen su protector, le echan todo, que él los proteja mañana. Es una visión, una óptica. Los murid tienen más orden, el muridismo es algo de masa. Yo cuando me enteré de que en Barcelona y Madrid iban a empezar el Ramadán ya no hago caso de un compañero, porque él no suele escuchar sobre este tema, la inmensa mayoría te dice: he llamado a Senegal. Si no hay Senegal no hay... Si te dicen que han llamado a Senegal es que han llamado a Tuba (la capital espiritual de los murid)".
}

Prueba de ello es también su proyección transnacional a través de redes comerciales y migratorias. Las investigaciones de la antropóloga Liliana Suárez, a propósito de la inmigración senegalesa en España y su capacidad para poner en 
marcha estrategias de superación de los marcos estatales, dan nuevas muestras del papel e importancia del muridismo: "Entre todas las cofradías, la murid ha adquirido una notable pujanza, afianzando su relativo control en los centros comerciales urbanos de Dakar por medio del establecimiento de cofrades en centros estratégicos del comercio al por mayor internacional, como Nueva York, París, Hong Kong, Milán, y otra multitud de ciudades europeas y norteamericanas" (Suárez, 1996: 28).

\section{LA COFRADÍA MURID: ESTRUCTURACIÓN Y ORGANIZACIÓN EN LA INMIGRACIÓN}

En su estudio de la influencia Tabligh ${ }^{8}$ entre la población inmigrante marroquí en Bélgica, escribía Felice Dassetto que "las cofradías clásicas funcionan de manera relativamente residual en relación con la sociedad inmigrada y sobre todo con las corrientes hegemónicas del İslam transplantado. En general, los miembros de las cofradías están relacionados y organizan reuniones religiosas en casas privadas. No está del todo excluido que en el futuro, en razón incluso de la recomposición en inmigración de las solidaridades segmentarias, las cofradías puedan encontrar bases nuevas de organización y expansión" (Dassetto, 1984: 121).

Parece que estas previsiones, al menos en lo que respecta a la inmigración senegalesa, se han cumplido. Ello no obsta para que, en ocasiones, entre el colectivo senegalés inmigrado se trate de minimizar el fenómeno de las cofradías. La desconfianza hacia un observador occidental, que puede malinterpretar su sentido y funciones, es quizás una de las razones de tal minimización:

"Se suelen reunir, yo no sé si se consideran ellos como daira, pero se suelen reunir. Y también de la misma manera que vienen aquí por ejemplo jefes murid, vienen también jefes tiyan. Para mí la finalidad es la misma, porque lo único que hacen es enseñar y recordar.

\footnotetext{
${ }^{8}$ Según el trabajo de Kepel en Francia "el Tabligh tiene por objetivo permitir al musulmán, individualmente, reencontrarse con la totalidad de su identidad islámica. Su meta es la reislamización de la sociedad pero, al contrario de los movimientos islamistas, lo hace por abajo, por el individuo. Es una organización de origen indio sin ninguna ambición política, nacida en 1927 en un país en el que los musulmanes eran franca minoría ahogados en el hinduismo. Para el impulsor del Tabligh en aquel entonces, el objetivo era que los musulmanes indios, en situación de aculturación, vistiendo como hindúes y celebrando sus fiestas, recuperaran una identidad verdaderamente islámica. En una sociedad no islámica, en donde los signos de pertenencia no son los del Islam y el poder no es islámico, se trata de recrear una estructura comunitaria que rompa con la lógica de la sociedad global, a partir de la reislamización de los individuos” (Kepel, 1993: 171-172).
} 
Solamente lo que sé es que hay gente, tres o cuatro personas, que se dedican por ejemplo a recoger las contribuciones y otras que se dedican a reunir a la gente o convocar si tienen reuniones. ¿Cómo te diría yo?: son vocales. Existe, pero no sé cómo funcionan realmente".

Sin embargo, ese sistema de estructuración en dairas (asociación o círculo religioso de la cofradía), así como las formas de organización de los hogares, trasladados desde el medio de origen hasta el medio de inmigración, se transforman en elementos reguladores del tipo de relaciones que los inmigrantes senegaleses establecen entre ellos mismos y con la sociedad de inmigración ${ }^{9}$. El trabajo de campo de Liliana Suárez en Andalucía también ha constatado que "la organización de las unidades domésticas senegalesas es la base de su expansión en el espacio migratorio y se definen por una organización jerárquica y una rigurosa división de funciones (...). Este característico modo de organización es una adaptación cultural inspirada en hábitos sociales de organización comunal fuertemente arraigados en Senegal, y especialmente en las regiones agrícolas wolof, de las que proceden la mayoría de los inmigrantes senegaleses" (Suárez, 1996: 27-28).

La etnia wolof (que es la etnia mayoritaria en Senegal y a la que pertenece el grueso de la inmigración senegalesa en España, y especialmente en Valencia ${ }^{10}$ ) constituye el núcleo de los efectivos de la cofradía murid. Es ésta la cofradía que ha experimentado un mayor crecimiento en los últimos años en cuanto al número de fieles, tanto en Senegal como en el contexto de la inmigración senegalesa en Valencia. De todos modos, y aunque suele haber un alto grado de correspondencia, no existe una adscripción total a las cofradías en función del grupo étnico de pertenencia:

"Eso no va por tribus, va más bien por los fieles. Realmente cada uno es libre de elegir, porque yo mismo pertenezco a la cofradía murid, pero tengo otro hermano que es tiyan. De todas maneras todo eso es ya como decir que, por ejemplo, el Islam es el árbol y entonces hay muchas ramas en este árbol. Todas estas ramas pertenecen al mismo árbol".

\footnotetext{
${ }^{9}$ Sobre la estructuración y organización de las dairas en inmigración pueden consultarse los artículos de Donald Carter "La formazione di una dahira senegalese a Torino" y "Una confraternita musulmana in emigrazione: i Murid el del Senegal”, ambos citados en la bibliografia.

${ }^{10}$ Entre 1994 y 1995 realizamos, con la financiación de la Institució Valenciana d'Estudis i Investigacions, un estudio sobre las condiciones de vida de los inmigrantes marroquies y senegaleses en el área de Valencia, que permitió corroborar el carácter homogéneamente étnico de la comunidad senegalesa (el total de los entrevistados era de etnia wolof) y un alto porcentaje de pertenencia a la cofradía musulmana murid. Véase J.Lacomba e I.Royo, 1995.
} 
En nuestra investigación hemos podido entrevistar en profundidad a cinco inmigrantes originarios de Senegal. De esos cinco entrevistados, tres eran de etnia wolof y pertenecían a la cofradía murid. De los otros dos casos, uno era originario de una familia de la cofradía tiyan y pertenecía a la etnia fulani, mientras que el último se asociaba a la cofradía qádir y era de etnia bámbara.

Además, también se han mantenido conversaciones informales con otros inmigrantes senegaleses a lo largo del trabajo de campo (en su mayoría musulmanes murid de etnia wolof). Así, por ejemplo, durante el proceso de investigación mantuvimos contacto con un núcleo familiar formado por una mujer marroquí (bereber originaria de la zona de Agadir) y un hombre senegalés (wolof y murid), con dos hijos (de dos y cinco años, escolarizados en un colegio público), que contrajeron matrimonio en inmigración y que comparten su vinculación cofrádica, reforzada - como reconocen ellos mismos - tras su unión religiosa. El marido (con diez años de residencia en Valencia) regenta una tienda de comercio al por mayor de suministros para la venta ambulante, en la que es ayudado por su mujer, y presenta el perfil del comerciante que asienta su mundo personal y de negocios sobre la pertenencia a la cofradía murid.

Tanto en este caso como en otros, la pertenencia cofrádica en contextos migratorios, permite superar algunas barreras o desplazar determinados límites que, seguramente, no se presentarían del mismo modo en origen. El caso francés es, en este sentido, uno de los más evolucionados. Sobre él cuenta Constant Hamés que "los muridies senegaleses también se implantaron en París: primero alrededor de la estación de Lyon, con vendedores ambulantes, y luego con una célula de estudiantes. Gracias al proselitismo de Abdoullaye Diéye en los círculos wolof parisinos, en el año 1977 nació la Asociación de Estudiantes e Interinos Muridies de Europa, que en 1983 se convirtió en el Movimiento Islámico de los Muridies de Europa, y publica la revista Ndigël-La voix $d u$ Mouride. En una de sus comunidades parisinas hay adeptos de varias nacionalidades: antillanos, franceses, alemanes, italianos, africanos, etc., y los no musulmanes pueden adherirse y participar" (Hamés, 1997: 550).

Esas comunidades están fundadas por un maestro (cheij), que predica a sus discípulos una vía mística, un camino hacia Dios, que los miembros de la cofradía aceptan y siguen. En esencia, las cofradías ponen en relación a un conjunto de actores sociales, reunidos según estatus en una red coordinada de funciones, que atribuye a cada uno tareas y responsabilidades específicas. Como toda organización, las cofradías o tariqas tienen sus normas y sus sistemas de sanciones y de promoción, así como un modo particular de lenguaje y de comunicación (Dassetto, 1984: 114-118).

La vida comunitaria de la cofradía gira en torno a dos clases de reuniones: unas, de periodicidad anual, y otras, semanales. A la reunión anual de los murid senegaleses ya hicimos referencia al hablar de la peregrinación a la ciudad de 
Tuba, conocida como magal. En cuanto a las reuniones semanales, éstas giran en torno a cuestiones de orden teológico, cantos religiosos o sesiones de lectura del Corán. De ambos tipos de encuentros, dice Hamès, que sirven para trabar "unas relaciones comunitarias muy fuertes, que refuerzan otras (de parentesco, de barrio, de sexo, de etnia, de clase social, etc.) o, por el contrario, permiten atravesar esas mismas fronteras sociales o políticas, de otro modo infranqueables" (Hamès, 1997: 298).

Las reuniones semanales de la cofradía cuentan con un ritual propio, en el que la repetición de letanías y el uso del rosario son elementos característicos, especialmente en el caso de la cofradía tiyaniya, que uno de los entrevistados (originario de una familia de la cofradía, pero que rechaza personalmente este tipo de práctica), relata así:

"Cuando termina as-salat (la oración) yo no voy practicar como los tiyani, eso es bida (no ortodoxo o ilegítimo), aunque todos los caminos son buenos para llegar al yanná (paraíso). Si los caminos van a tener otra manera y van a tomar un camino que va a molestar a la gente y a tener mucho poder, para mí no... Los tiyani cuando lo hacen están dos o tres horas así (pasando las bolas del rosario). Pero Mohammed (Mahoma) dice que hay que practicar el Islam y que cuando se termina de rezar hay que salir para buscar la vida".

De todas maneras, el uso del rosario no es exclusivo de esta cofradía, pues también se utiliza como parte de las prácticas individuales por otros musulmanes. Por ejemplo, el entrevistado de la cofradía qadiriya afirma igualmente usarlo de forma habitual, y no como voto contraído, tal como hacen en la mayoría de casos los tiyan:

\footnotetext{
"Son diferentes. Bueno, diferentes entre comillas. Por ejemplo uno después dice cien veces el nombre de Alá, otro doscientas... Es como un contrato. Yo no lo he cogido, pero es algo que si lo coges no debes dejarlo. Te comprometes a hacerlo después de rezar. A veces ves a gente contando con el rosario, incluso jóvenes y todo. Es un compromiso que algunos han hecho y que tienen que seguir. Antes daba tiempo: estás en casa, te levantas, te duchas, rezas, te sientas, haces lo que tienes que hacer y sales. Pero ahora con tantos problemas sales a la calle y... Yo tengo uno rosario pequeño, de treinta y tres nombres".
}

El ritmo de esos encuentros semanales es un elemento estructurador de la vida social ordinaria. Hamès lo describe como "momento repetido, tranquilizador, de encuentros familiares, lugar de intercambio de informaciones amistosas, ocasión, sobre todo para las mujeres, de salir un poco de casa, lugar de comadreos y toda clase de transacciones, vector también de la emoción religiosa, todo esto es la cita de la cofradía, que en definitiva proporciona el pretexto y el motor de la 
sociabilidad local" (Hamès, 1997: 299).

Es más, la daira (el círculo semanal) también se emplea para celebrar y oficiar determinados acontecimientos y ritos de paso: nacimiento, atribución de nombre, boda o defunción. Asimismo, las dairas dan cabida y se convierten en correas de transmisión de las relaciones que los adeptos de las cofradías mantienen con su líder espiritual respectivo, basadas en el sistema de donaciones y contra-donaciones.

\section{SOCIABILIDAD Y SOLIDARIDAD COFRÁDICAS}

Hemos visto hasta ahora cómo las cofradías musulmanas, y la cofradía murid en particular, son motores de la sociabilidad de sus miembros. También lo son, como trataremos de mostrar a continuación, de los lazos de solidaridad. Pero, para entender con mayor precisión ambas dimensiones (sociabilidad y solidaridad), es necesario analizar más a fondo cuál es el significado y las múltiples funciones sociales que las cofradías desempeñan.

Las funciones a las que nos referimos se sitúan a un doble nivel: 1) el recurso a la cofradía puede tener una función terapéutica; 2) la pertenencia a la cofradía crea una serie de vínculos sociales y recompone las relaciones de sus miembros. Por ello, dice Constant Hamès, la cofradía "nunca es una red de afiliación socialmente neutra, que se superpone por las buenas a una organización social acabada y sólo tiene sobre ella efectos religiosos de orden psicológico individual" (Hamès, 1997: 288-289).

La participación en el sistema cofrádico puede tener efectos psicológicos y terapéuticos a nivel personal (de hecho, los medios utilizados mezclan los efectos catárticos, la utilización de la farmacopea tradicional, la brujería y la adivinación); no obstante, sus principales funciones se encuentran en el terreno de la organización social. Vinculando ambas dimensiones, Felice Dassetto apunta que "el recurso a los santos puede explicarse por su función mediadora entre Dios y los humanos, pero también por la falta de soluciones sociales a los problemas sanitarios y societarios (...). En general, el éxito de los santos puede comprenderse en el contexto de una modernización desestructurante e inacabada" (Dassetto, 1984: 44).

También Sossie Andezian relata, en su estudio de las cofradías magrebíes, cómo "la pertenencia a un grupo de cofradía confiere al individuo una identidad social, aunque se limite al ámbito restringido de los miembros de la misma cofradía (...) La afiliación a una cofradía acarrea la obligación moral de participar en un sistema de intercambios, por una parte con los superiores jerárquicos, y por otra con los hermanos espirituales. Cada orden transmite una serie de valores presididos por el amor y la fraternidad" (Andezian, 1997: 493). Se pone así de manifiesto que la noción y la puesta en práctica de la solidaridad comunitaria 
no son totalmente exclusivas de los senegaleses murid. Más bien son el contexto de modernización desestructurante y la necesidad de identidad social los que deben considerarse como los principales factores explicativos del éxito de las cofradías, al favorecer especialmente las relaciones comunitarias. Sin embargo, sí existen diferencias en cuanto al tipo de ayuda mutua que desarrollan los murid senegaleses y, sobre todo, su exportación y mantenimiento en el ámbito migratorio, como son: 1) el sentido de la jerarquía de edades; 2) la organización y el respeto en el cumplimiento de las tareas domésticas; 3) la filosofia del éxito personal, que sólo puede buscarse en el grupo y para el grupo.

En esta línea, afirma Ottavia Schmidt que la fuerza y originalidad de la emigración senegalesa parece residir en su eficiente organización de la solidaridad, que considera de forma negativa el individualismo, de tal modo que la solidaridad senegalesa no tiene carácter voluntarístico o de emergencia, sino que forma parte de un estilo y de un sistema de vida que tiene raíces culturales e históricas profundas. Asimismo, propone valores y modos para realizarlo, como el propio sistema murid (Schmidt, 1994: 88-89).

En nuestro ámbito, habría que preguntarse hasta qué punto esa recomposición de las solidaridades en el contexto de la inmigración (a través del sistema de cofradías) no está influenciada también por la experiencia de la exclusión socioeconómica y las dificultades a la inserción en la sociedad de acogida:

\footnotetext{
"Yo mismo cuando estaba en África no me vinculaba con las cofradías. Pero al estar aquí y perder casi esta costumbre, esta cultura, pues cada vez que viene un marabut tengo ganas de ir a verlo y escucharlo. Porque sé que realmente es una ayuda moral, te da más fuerza para seguir luchando saber que hay gente que sigue todavía dependiendo de ti y esperándote. Realmente el marabut, si fuese una persona egoísta, pues lo tendría también fácil, porque la gente cree y tiene fe en él, pero él mismo te dice que viene en tercer lugar: primero cumple con tus obligaciones, el trabajo, tu familia y luego yo. Y decir yo es decir los necesitados que están alli".
}

En general, la solidaridad y la asistencia acompañan todo el camino del inmigrante senegalés, desde la partida a la llegada, en la vida de todos los días, en las dificultades que puede encontrar durante su permanencia lejos de casa hasta el regreso. La solidaridad se convierte en un refuerzo contra los riesgos inherentes a la vida precaria del inmigrante (Schmidt, 1994: 86). El sistema de ayuda recíproca en inmigración se extiende desde la provisión de las condiciones de acogida a la llegada (casa, comida, dinero, trabajo...) hasta la ayuda para el regreso, pasando por gastos por enfermedad, celebraciones familiares o repatriación de connacionales en caso de fallecimiento:

"Si hay un problema, si una persona está mal o está en el hospital y hay que ayudarle, hacemos todos algo y sacamos el dinero para ayudarle. Si está muy enfermo damos 
todos dinero para ayudarle. Si una persona se muere cuesta mucho dinero llevarlo hasta nuestro país, entonces escribimos hasta Italia y pedimos ayuda. Si yo tengo un amigo que está allí yo le diré: Mira, diles a tus amigos que recogemos dinero. Lo ponemos dentro de un banco para venir aquí y luego éste que ha muerto lo llevaré a mi país, y el dinero que sobra se lo daré a su familia. Así lo organizamos los senegaleses. Siempre así de esta manera".

Asimismo, en el contexto migratorio los mecanismos comunitarios y de solidaridad senegaleses dejan un tanto de lado la influencia de la pertenencia étnica. Las diferencias étnicas se diluyen en favor de la solidaridad mutua entre connacionales como garantía de supervivencia y de previsión social. A ello contribuye el hecho de que las divisiones étnicas en Senegal parecen tener, al menos a ojos de los inmigrantes, efectos menos distanciadores que en otros países:

"En Senegal no es como en otros sitios que hay enfrentamientos entre las etnias. Tú puedes ser de tal o tal etnia, pero eso no tiene importancia. Hasta nuestro primer presidente era cristiano, y si preguntas a la gente muchos te van a decir que prefieren a Senghor que al de ahora".

Todo ello viene a reforzar la idea de que, a través de la pertenencia a la cofradía, se puede encontrar un marco mítico-ritual que permite explicar e interpretar la experiencia migratoria, al tiempo que reducir las contradicciones inherentes a esta situación. Al respecto, escribe Sossie Andezian que "se asiste en el contexto migratorio a una redefinición de los roles familiares, los roles sexuales, el espacio privado y el espacio público. El carácter religioso de las actividades de grupo no puede más que legitimar las decisiones relativas a las reglas a adoptar. La religión forma parte de esas actividades ritualizadas, donde las reglas fundamentales de una sociedad deben ser observadas con el mayor rigor. La ritualización es más que nunca necesaria aquí para compensar la ausencia de instancias de control de los cambios" (Andezian, 1981: 263).

Las funciones y el papel que el marabut o cabeza de la cofradía desempeña no sólo en el país de origen, sino también en inmigración, a través de sus visitas periódicas a los fieles senegaleses, apuntalan esta hipótesis:

"El marabut también tiene varias funciones. El marabut es como el profesor: él te enseña el Corán, a leer, a practicar. Te enseña también a ser un buen musulmán y te enseña el camino recto para no, por ejemplo, pecar (...) Muchas veces la gente puede llegar hasta a olvidarse de sus principios, de sus propias ideas, de quienes son realmente, entonces el marabut ¿qué hace?: pues recordárselo, estar presente en el momento adecuado para recordarles que vienen de otras tierras lejanas, habéis salido de esas tierras y estáis aquí entonces para trabajar, hay que seguir trabajando y hay que 
saber lo que habéis dejado atrás. Atrás hay gente que os necesitan. Y no solamente es el marabut que habla la persona que deben ayudar, porque el marabut pone primero lo principal (la familia), el trabajo, y luego viene él en tercer lugar".

Además, el encuentro periódico con el marabut, o con alguno de sus discípulos desplazados, se convierte en una ocasión que permite recrear lazos de amistad y solidaridad entre los asistentes al acto, máxime cuando se trata de personas dispersas en el territorio, que pueden acudir desde diferentes provincias y movilizarse para ello incluso alquilando autobuses para la ocasión:

"Y también te ves con muchísima gente. Yo cada vez que voy cuando viene un marabut me veo con gente que hacía años que no y que no sé por dónde están. Cada vez que hay un marabut vas a ver a esta gente y eso crea una cierta cordialidad. Está muy bien".

Es en la recepción de los marabuts llegados de Senegal, que llegan a realizar auténticas giras por distintos países europeos, donde se demuestra una vez más la capacidad organizativa de los inmigrantes musulmanes senegaleses (en especial de los murid):

\footnotetext{
"Ellos se suelen hospedar en hoteles, y luego pues se suele alquilar una planta del mismo hotel y allí se reúne toda la gente de la comunidad. Lo único que suele hacer el marabut es agradecer a la gente su masiva presencia, aconsejarles y luego pues la gente contribuye. Pero no es el dinero que dan para él. Desde luego pagamos su estancia aquí, sí (...) Lo de los hoteles resulta carísimo. Esta vez nos gastamos algo más de cuatrocientas mil pesetas (...) Sí, claro lo recogido es muy superior, porque eso ha sido sólo para los gastos: el hotel, la comida, el transporte... Pero también hay muchos senegaleses. Hay muchos".
}

La mencionada suma, aunque no es generalizable, resulta indicativa del volumen de dinero que puede recolectarse durante el encuentro con el marabut y, por tanto, de la importancia económica del acontecimiento:

"Hay veces que se recoge más que otras. Es muy relativo. Por ejemplo, cuando se trata de un jefe muy importante que se ha desplazado, esto supone más gastos porque viene con más gente. Entonces a cada uno se le exige una cotización de tanto dinero. Y otras veces pues se dice que cada uno da lo que puede".

\section{MURIDISMO: EL NEXO ENTRE ECONOMÍA Y RELIGIÓN}

Al igual que su dimensión comunitaria y solidaria, el componente económico 
del sistema murid es fundamental para entender su éxito como estrategia de inserción en la nueva sociedad, sobre todo cuando la religión ya no ocupa aquí la misma posición que en la sociedad de origen.

Ottavia Schdmit va más allá en su estudio de la inmigración murid senegalesa en Italia, y concluye que no se debe ver en la organización murid sólo una forma particular de solidaridad africana. Para ella se trataría de algo más complejo y más original, "en donde se entremezclan elementos de la sociedad jerárquica tradicional, de la cultura islámica y del productivismo y consumismo modernos" (Schmidt, 1994: 111). Tanto es así que para Jean Copans "hay entre el muridismo y el desarrollo económico un lazo idéntico al que existe entre el protestantismo y el capitalismo en la hipótesis weberiana" (Copans, 1980: 51). Sin entrar a valorar el grado de profundidad de ese paralelismo ${ }^{11}$, no puede dejar de señalarse la relación existente entre determinadas actividades económicas y un particular sistema de creencias y prácticas religiosas en el caso que nos ocupa:

\footnotetext{
"Ahora la mayoria son murid en Tuba y en Senegal. Algunos que hacen cosas no son murid. Si eres comerciante tienes que poner una foto de Tuba, si no mucha gente no va a entrar. Hasta los tiyan, si son comerciantes, se ponen una foto de Sid Ahmed Bamba en Tuba. Casi todos".
}

Esas actividades económicas hacen referencia, en primer lugar, al cultivo del cacahuete en Senegal (principal producto agrícola para la exportación) tradicionalmente organizado a partir del sistema murid: "La base agronómica, económica y social de la cofradía murid es evidentemente el cacahuete. Ese lazo, que algunos han calificado de fortuito, explica la significación estratégica del trabajo agrícola que produce a la vez el cacahuete y el muridismo" (Copans, 1980: 94). En segundo lugar, y en lo que respecta al ámbito de los países de inmigración, el tipo característico de actividad económica asociado a la organización murid es el de la venta ambulante.

Lo más significativo es que ambos tipos de actividad económica (cultivo del cacahuete y venta ambulante) parten en su concepción y organización de una misma filosofía del trabajo. La piedra angular resulta ser una división de competencias, que se traduce en delegar al marabut la plegaria y la meditación, mientras el discípulo se ocupa, mediante el trabajo, de la prosperidad de la comunidad. Además, la sustitución de la plegaria por el trabajo otorga a este

\footnotetext{
"Una formulación más amplia de esa tesis puede encontrarse también en el trabajo de Jean Copans et al. (1972).
} 
último un sentido de redención (Schmidt, 1994: 13).

Liliana Suárez también incide en lo mismo, cuando señala que "la eficacia de la estructura socioeconómica murid se basa en una ideología que enaltece el trabajo duro, los sacrificios cotidianos, y las privaciones de la vida en el extranjero como actividades santificantes que emulan los sacrificios en el exilio del santo fundador Cheij Amadou Bamba en la época colonial" (Suárez, 1996: 29).

Es éste el caso, en su expresión más extrema, de los Bay Fall, un subgrupo en el interior del muridismo, que sigue de forma rígida esa máxima. Los Bay Fall entremezclan actividad religiosa y actividad laboral, no cumplen las cinco oraciones diarias prescriptivas, no hacen el Ramadán y no peregrinan a la Meca, sino a Tuba (la ciudad en la que naciese Amadou Bamba, convertida hoy día en el centro espiritual de los murid senegaleses), con el fin de dedicar todo su tiempo al trabajo:

"El Bay Fall es parte también del muridismo, pero en este caso es el ejemplo del árbol y sus ramas. El Bay Fall viene a ser una rama pequeña, una rama corta de lo que es el muridismo. El Bay Fall es el trabajador. Los Bay Fall son seguidores de uno sacrificó toda su vida trabajando para Serigne Bamba. Si vas a Tuba, por ejemplo, verás que hay muchos, muchos Bay Fall, y realmente ¿a qué se dedican?, pues a estar trabajando para los marabuts. Pero no para equis marabuts, sólo para un marabut (...) El que creó esta rama, este señor trabajó toda su vida para el que era el jefe de los murid. Era su valido. Entonces este gran marabut, este jefe, le dijo que era el tiempo de Ramadán y que había que ayunar, y él con la fe que tenía fue a su casa y exigió a su mujer, a sus hijos, hasta a los gatos sin comer ni beber. Le llamó el marabut y le dijo que no era así el ayuno, que también hay que romperlo durante la tarde. Y según tengo entendido el marabut le dijo que para su ayuno que él se encargaba, y lo dijo para que no matara a sus animales o a sus hijos. Y él siguió trabajando".

Los Bay Fall son los que dan la imagen más completa del sacrificio personal con un objetivo no terrenal, tratando de redimirse a través del trabajo intenso y renunciando a cualquier tipo de lujo:

"Un Bay Fall tiene que ser una persona que no quiere nada del mundo. No quieres el lujo por ejemplo. Tiene que tener unos zapatos, una camiseta, un pantalón, una mujer, una habitación, y bueno, un animal. Lo demás todo lo que trabaja por su sudor. Por ejemplo, como Sid Ahmed Bamba que es el gran marabut de la religión de los murid. Es su seguidor el que le va a ayudar para que el tenga tiempo para hacer las cosas de Dios. El Bay Fall sale de ahí, porque el Bay Fall trabaja siempre para el gran marabut. No tiene que tener nada, ni dinero ni nada, todo lo que trabaja es para el gran marabut. Bueno el marabut también tiene que garantizar para los que han estado trabajando para Dios". 
RIS

REVISTA INTERNACIONAL DE SOCIOLOCIÁ

No 29, Mayo - Agosto, 2001

JOAN LACOMBA

Por otra parte, no es casual que haya sido la venta ambulante la actividad económica desarrollada preferentemente por los inmigrantes senegaleses. La razón de ello es doble. La primera, es que la venta ambulante es uno de los escasos nichos laborales ${ }^{12}$ que el mercado ha dejado sin cubrir en las economías de los países occidentales de inmigración. La segunda, y principal razón, es que la venta ambulante se adapta al carácter informal de las actividades económicas que mayoritariamente realiza la población senegalesa en su propio país.

Sobre este último extremo, Serge Latouche cuenta que "un sociólogo de Dakar y el equipo Chodak (Paro en Dakar) de ENDA (Medio Ambiente y Desarrollo del Tercer Mundo) se interesaron por el modo de vida de las poblaciones del Gran Yoff, una de las barriadas más desheredadas de Dakar. La estructura reticular permite a unas familias medias de doce personas disponer de un ingreso monetario siete veces superior a los recursos oficiales. El sector informal es objeto del debate, pero los productos de la actividad informal no explican directamente su especificidad; la acumulación de los derechos sobre las diferentes redes en las que participan los miembros de la familia es la fuente directa de la renta complementaria, y no las ventas de bienes y servicios. Una intensa circulación de donativos en dinero, de inversiones, de anticipos, de reembolsos, de contribuciones, se ve cubierta por una importante producción de bienes, suministro de servicios, entrega de mercancías. Todo esto se inscribe en unos circuitos complejos: donativos por nacimiento o matrimonio, regalos, empréstitos voluntarios o forzosos, etc. (...) En realidad, el economista no capta más que una parte del aspecto económico de esa realidad compleja, pues la mayor parte se halla tan inmersa en la vida social que no es fácilmente discernible" (Latouche, 1993: 100). En sintonía con esta argumentación, Bruno Etienne reconoce que, en general, los inmigrantes (como en el caso que nos ocupa) se han limitado a importar una característica de las sociedades periféricas, que consiste en un desarrollo exacerbado de la economía subterránea de pequeños oficios y de la articulación de las economías étnicas y familiares (Etienne, 1987: 297).

Por su carácter informal, la venta ambulante permite a los inmigrantes senegaleses mantener una lógica mercantil y comercial semejante a la que desarrollan en gran parte de las actividades económicas en su país de origen, al tiempo que les ayuda a no apartarse de su vinculación con la cofradía murid: "Los vendedores ambulantes que distribuyen sus inventarios de baratijas made in Hong-Kong a través de Francia pertenecen en general a la gran familia de la

\footnotetext{
${ }^{12}$ Sobre la cuestión del mercado de trabajo de los inmigrantes en España y los nichos laborales puede consultarse el artículo de Marcos y Rojo (1991).
} 
cofradía de los murid. El muridismo senegalés fue fundado en la época colonial por cheij Amadou Bamba, para sustraer a los musulmanes del proselitismo de los misioneros cristianos, encuadrándolos estrechamente. Hoy en día se reencuentra en la organización práctica de la emigración. Los cheijs de las cofradías, propietarios de cultivos de cacahuetes, envían a sus fieles para que ayuden a los más necesitados, puesto que el precio de los productos oleaginosos ha bajado. Los inmigrados navegan entre Dakar y Burdeos, vuelven a la orden del cheij, parten o son reemplazados por novicios. Cien mil ambulantes, venidos de Senegal, pertenecen a esta secta, sin contar los clandestinos" (Krieger, 1985: 126).

El destino de los recursos económicos generados por el sistema socio-religioso murid en inmigración es doble: una parte del dinero es enviado directamente a los familiares; el otro es transferido como donativo a las cofradías (en un porcentaje del que no existen cifras fiables, pero que podría ascender a una cantidad significativa). En la primera dirección, las economías de consumo familiares son el destino más habitual de los flujos de dinero procedentes de la migración:

\footnotetext{
"Envio dinero, porque mi padre tiene setenta y cinco años. Entonces ya no puede trabajar. En Senegal no es como aquí, no pagas seguridad social ni nada y no hay jubilación, entonces es muy difícil. Cada uno tiene que mantener a sus hijos, a su familia. No están muy mal, pero tienes que tener hijos o tienes que tener familia. Entonces si tienes familia alguno puede mantenerla y si tienes hijos también hay que darles de comer. Ser viejo es ser como un rey. Yo desde el año ochenta y cuatro hasta hoy mi padre no sabe cuánto dinero cuesta. A veces mando un poco de dinero para cada uno, para su bolsillo. Y comida mando a un comerciante que mande a mi casa por veinte mil o treinta mil. Yo compro la comida por cuatro meses. A veces mando más, porque el comerciante quiere dinero también por trabajar".
}

Pero la vivienda, dadas las dificultades de acceder a ella a causa de los salarios en el país de origen, también ha pasado a constituir uno de los sectores predilectos de la inversión de los migrantes internacionales senegaleses:

"Para los que vivimos en Dakar la vida es mucho más cara que en los pueblos, entonces tenemos más gastos, porque un piso vale más o menos diez millones de pesetas. Si quieres vivir bien hay que buscar todo ese dinero. Entonces ¿cómo vamos a vender bueno, bonito y barato?. Por lo menos si trabajas aquí hay que ganar lo que ganas en el campo, por lo menos ochenta mil pesetas cada mes, que son cuatrocientas mil de mi país. Entonces tengo el mismo salario, el mismo sueldo que un ministro de alli".

Esa tendencia tiene efectos múltiples sobre la sociedad y el tejido urbano 
RIS

REVISTA INTERNACIONAL DE SOCIOLOGí

№ 29, Mayo - Agosto, 2001

JOAN LACOMBA

de Senegal: "Los migrantes internacionales, inversores dinámicos en el sector inmobiliario, constituyen una alternativa al desentendimiento del Estado. En efecto, la reducción drástica de las subvenciones estatales a las sociedades inmobiliarias ha sumido a estas últimas en una crisis financiera que les impide realizar sus programas de alojamiento. Los emigrados, que disponen de recursos financieros considerables, parecen haber tomado el relevo. Adquieren de segunda mano unos terrenos en la periferia de la ciudad donde realizan en períodos relativamente cortos construcciones duras. Contribuyen así a la extensión y sobre todo a la revalorización de zonas urbanas y caracterizadas hasta ese momento por su precariedad. Además, en el cercano extrarradio los migrantes internacionales se apropian de casas que transforman para alquilarlas a precios accesibles a los funcionarios y otros empleados del sector informal excluidos de los programas de vivienda planificada" (Tall, 1994: 137).

Pero también hay que establecer diferenciaciones, de acuerdo con la estratificación existente en el interior de la comunidad y las posibilidades económicas de los propios inmigrantes senegaleses: "La localización de las inversiones inmobiliarias está ligada a la vez a la pertenencia étnica, al itinerario migratorio y a la ocupación profesional del emigrado. Los migrantes partidos recientemente construyen casas más modestas, salvo los que se han enriquecido mediante tráficos dudosos o mediante un comercio próspero. En las nuevas extensiones de Pikine, encontramos inmigrantes cuya fecha de partida es reciente. La casi totalidad de los inmigrantes encontrados en esta zona se han establecido en los nuevos países de acogida europeos (Italia, España) ${ }^{13}$. Ellos participan en la producción urbana de estos nuevos frentes de urbanización" (Tall, 1994: 143).

Es, por ejemplo, el caso de uno de nuestros entrevistados, originario de una zona periférica de la capital (el barrio de Pikine). Éste confirma su contribución regular a la economía familiar y la vivienda, al tiempo que destaca la presencia de senegaleses inmigrados como procedentes de la misma zona de Dakar:

"De alrededor sí, hay muchos en Murcia, Alicante... Hay alguno que no conozco, porque cuando salí eran muy pequeños. A veces me dicen: Yo soy de Pikine, ¿te conozco. Y digo: No, no me conoces. Parezco mi hermano. Sí, hay bastante gente".

En la segunda dirección (la de las transferencias económicas directas a las cofradías), el dinero que los inmigrantes entregan como donativo se destina

\footnotetext{
${ }^{13}$ En relación con los nuevos países de acogida, algunos de los inmigrantes senegaleses entrevistados valoran positivamente a España e Italia como destinos atractivos por dos razones: una mayor presencia de la economía sumergida e informal y un menor rechazo de la población en comparación con otros países europeos.
} 
mayoritariamente a obras sociales y culturales: cajas de asistencia social, construcción de escuelas, dispensarios médicos, mezquitas u obras públicas (alumbrado, alcantarillado, etc.). Por ejemplo, una de las construcciones más emblemáticas financiada de esta manera, además de la gran mezquita de Tuba, ha sido la del hospital de la misma ciudad:

"En una ciudad santa que hay allí, que llamamos Tuba, se está construyendo un hospital, y los que realmente están dando una participación pues son los inmigrantes en general. Eso, por ejemplo, ya no hace falta ser murid o tiyan para participar porque es un acto muy bonito y esto puede ayudar a los de la ciudad de allí. Hay representantes, que colectan ese dinero y lo mandan alli. $O$ cuando viene aquí el marabut se le da. Los canales son de muchos tipos".

De la misma manera se ha financiado un gran número de escuelas coránicas que suplen, en gran parte, las carencias de la red educativa estatal:

“Allí hay escuelas coránicas y que no reciben por ejemplo subvenciones del gobierno, entonces son los propios devotos los que deben mantener el funcionamiento de estas escuelas".

Así, a través de la socialización educativa escolar, las nuevas escuelas coránicas se convierten también en centros de reproducción del sistema marabútico. Con ellas se completa el círculo de una compleja dinámica organizativa en la que no están ausentes las formas de clientelismo religioso:

"Hasta la edad de seis tengo que aprender la religión, el Corán. Allí lo aprendes con un marabut que va a tener su escuela en su casa. La gente del pueblo mandan sus hijos para aprender el Corán. Y así, cuando terminas de aprender el Corán tienes que ir a buscar otro marabut que te va a enseñar la charia. Yo he seguido lo mismo desde la casa de mi padre, que tenía muchos alumnos para aprender el Corán. Luego, para estudiar más la religión, tienes que ir un poco lejos de tu familia. Fui a otro pueblo donde hay otro marabut más grande que mi padre. Significa que tiene más alumnos que aprenden allí la religión islámica".

Asimismo, el fenómeno cofrádico tampoco se encuentra exento de las rémoras que se han asociado a él. En el ámbito de la inmigración algunos individuos que se autodefinen como marabuts utilizan a los fieles para obtener beneficios personales. Por ejemplo, Anne Krieger relata cómo, en Francia, "los cheijs han pululado en busca de los vendedores ambulantes para sostenerlos en su presencia espiritual. Incluso allí se ha producido un cambio y muchos de los marabuts son charlatanes que prometen usar su influencia para espantar los malos espíritus. Algunos se dicen capaces de eliminar el mal de ojo, de proporcionar suerte y 
virilidad o de reconciliar las parejas desunidas" (Krieger, 1985: 127).

\section{CONCLUSIONES}

Las formas de estructuración y organización cofrádicas entre la inmigración musulmana senegalesa muestran el potencial del Islam murid en contexto de inmigración, reconocido por diversos estudios como un importante factor a tener en cuenta en la inserción del colectivo ${ }^{14}$. La vinculación con la cofradía murid permite a los inmigrantes senegaleses poner en marcha diferentes estrategias de inserción, de acuerdo con su relación y su posición dentro de la misma. El estudio del sistema de organización y solidaridad murid en inmigración nos muestra la conjunción de estrategias individuales con otras estrategias más complejas y sistemáticas.

A pesar de su carácter comunitario, el sistema murid da cabida también a múltiples iniciativas individuales. Por ejemplo, la mediación de la cofradía entre los inmigrantes y la sociedad de acogida, puede servir a los jóvenes dotados de iniciativa comercial para beneficiarse del sistema de solidaridad murid y alcanzar así objetivos personales. En otros casos se participa de este tipo de organización y solidaridad migratoria sin que se comparta en su totalidad el espíritu ni las prácticas de la cofradía.

Se constata al respecto que existe una estratificación en el interior del propio colectivo inmigrante senegalés y que su vinculación con la cofradía como estrategia de inserción adopta diferentes objetivos y niveles de adhesión. Así, puede construirse una tipología que distinga tres grupos de inmigrantes senegaleses murid:

1) Los jóvenes rurales que vienen como voto mediante la cadena migratoria murid, trabajan mayoritariamente en la venta ambulante, viven en condiciones precarias y envían dinero a casa y a la cofradía. Son también los que regresan a Senegal tras un período migratorio relativamente corto.

2) Los jóvenes urbanos con un nivel medio-alto de estudios e iniciativa empresarial, que pasan a controlar la distribución comercial ligada a la venta ambulante, y que mantienen una relación ambigua, cuando no instrumental, con las cofradías. No tienen un proyecto de retorno claro y su periplo migratorio puede llevarlos por diferentes países hasta ver cumplidas algunas de sus expectativas.

3) Los más mayores, que buscan una colocación estable y una reputación

\footnotetext{
${ }^{14}$ Por ejemplo, Liliana Suárez llega a la conclusión de que, aunque su trabajo de campo sugiere que la inmigración senegalesa es más heterogénea que lo que describen otros autores concentrados en el fenómeno murid (Elbin, Carter y Schmidt di Friedberg), su vigor y eficacia están fuera de duda y representa un impulso que inspira a toda la comunidad senegalesa en general (1996: 28).
} 
dentro del propio colectivo inmigrante, manteniendo y desarrollando el sistema de organización murid. Tienen un nivel medio de interacción con la sociedad de acogida, pero sobre todo tratan de no perder los vínculos y la influencia en la comunidad de origen, pues a la larga regresarán a Senegal. El carácter comunitario de la organización murid favorece la actuación de los miembros de este grupo como mediadores entre los inmigrantes senegaleses y la sociedad de $\operatorname{acogida}^{15}$.

\section{BIBLIOGRAFÍA}

AGUER, B. (1991), "Résurgence de l'Islam en Espagne", Revue Européenne des Migrations Internationales, vol. $7, \mathrm{n}^{\circ} 3$, pp. 59-76.

ANDEZIAN, S. (1981), "Appartenance religieuse et appartenance comunautaire: l'exemple d'un groupe d'immigrés algériens en France", Annuaire de l'Afrique du Nord, pp. 259-266.

(1997), “Argelia, Marruecos y Tunicia”, en G.Veinstein y A. Popovic (eds.), Las sendas de Allah, Barcelona, Edicions Bellaterra, pp. 477-500.

ANTOINE, P. y P. BOCQUER (1995), "L'insertion urbaine à Dakar. Les juenes vivent la crise, les aînés la supportent”, Orstom Actualités, n 48, pp. 16-22.

CAMPUS, A. y L. PERRONE (1990), "Senegalesi et marocchini: inserimento nel mercato del lavoro e progetti migratori a confronto", Studi Emigrazione, n 98, pp. 191-219.

CAMPUS, A., G. MOTTURA y L. PERRONE (1992), "I senegalesi", en G.Mottura (ed.) L'arcipelago immigrazione. Caratteristiche e modelli migratori dei lavoratori stranieri in Italia, Roma, Ires-Ediesse, pp. 249-275.

CARTER, D. (1991a), "Una confraternità mussulmana in emigrazione: i murid del Senegal", Religioni e Società, $\mathrm{n}^{\circ} 12$, pp. 60-78.

(1991b), "La formazione di una dahira senegalese a Torino", IRES. Uguali e diversi, Torino, Rosenberg \& Sellier, pp. 109-131.

COPANS, J. (1972), Maintenance sociale et changement économique au Sénégal. Doctrine économique et pratique du travail chez les Mourides, París, Orstom.

${ }^{15}$ Para el conjunto de los colectivos migratorios la figura del mediador social o intermediario coincide con el perfil de una persona que reside desde hace tiempo en el país de inmigración, tiene un conocimiento apreciable de su lengua y su cultura, y goza de un cierto prestigio. Su papel es actuar como portavoz del colectivo y, sobre todo, como instancia de resolución de los conflictos generados en las relaciones entre los inmigrantes y el resto de la sociedad. 
(1980), Les marabouts de l'arachide. La confrérie mouride et les paysans du Senegal, París, Le Sycomore.

DASSETTO, F. (1984), L'Islam Transplanté. Vie et organisations des minorités musulmanes en Belgique, Bruxelles, Evo.

(1993), Il ritorno dell 'Islam: i musulmani in Italia, Roma, Edizioni Lavoro.

(1994), L'Islam in Europa. Torino, Fundazione Giovanni Agnelli.

DIOP, M. (1985), “Les associations Murid en France”, Esprit, nº 6, pp. 197-206.

(1988), "Stéréotypes et stratégies dans la communauté musulmane de France", en R. Leveau y G. Kepel (eds.), Les musulmans dans las société française, París, PFNSP, pp. 77-87.

(1989), "Immigration et Religions: Les musulmans négro-africains en France", Migration et Société, vol. I, 5-6, pp. 45-57.

(1990), "Un aperçu de l'islam négro-africain en France", Migrants-Formation, $\mathrm{n}^{\circ} 82$, pp. 77-81.

(1994), "Structuration d'un résau: la Jamaat Tabligh (Société pour la Propagation de la Foi)", Revue Européenne des Migrations Internationales, vol. 10, $\mathrm{n}^{\circ}$ 1, pp. 145-154.

ETIENNE, B. (1987), L'Islamisme radical, Paris, Hachette.

ETIENNE, B. y R. LEVEAU (1990), L'Islam en France, Publications Annuaire de l'Afrique du Nord, París, CNRS.

GOZÁLVEZ, V. (1995), Inmigrantes marroquies y senegaleses en la España mediterránea, Valencia, Conselleria de Treball i Afers Socials.

HAMÈS, C. (1997a), "Cofradías, sociedad y sociabilidad", en G. Veinstein y A. Popovic (eds.), Las sendas de Allah, Barcelona, Edicions Bellaterra, pp. 287-299.

(1997b), "Europa occidental contemporánea", en G. Veinstein y A. Popovic (eds.), Las sendas de Allah, Barcelona, Edicions Bellaterra, pp. 545-551.

KAPLAN, A. (1998), De Senegambia a Cataluña. Procesos de aculturación e integración social, Barcelona, Fundación La Caixa.

KEPEL, G. (1987), Les Banlieues de l'Islam, París, Seuil.

(1993), “El Islam en Francia. ¿Inserción o integración?”, en B. López (ed.), Inmigración magrebi en España. El retorno de los moriscos, Madrid, Mapfre, pp. 161-180.

KRIEGER, A. (1985), Les musulmans en France. Religion et culture, París, Maisonneuve et Larose. 
LACOMBA, J. (1996), "Los factores culturales en la inserción de los colectivos migrantes. El caso de la inmigración musulmana", Cuadernos Citmi, n 1, pp. 59-68.

(2001), El Islam inmigrado. Transformaciones y adaptaciones de las prácticas culturales y religiosas, Madrid, Ministerio de Educación, Cultura y Deportes.

LACOMBA, J. y N. DEL OLMO (1996), La inmigración musulmana y su inserción. Musulmanes en Valencia, Papers Sud-Nord $\mathrm{n}^{\circ} 1$, Universitat de València.

LACOMBA, J. e I. ROYO (1995), Estudio de las condiciones de vida de los inmigrantes marroquies y senegaleses en situación irregular en el área urbana de Valencia (Memoria de investigación), Institución Valenciana de Estudios e Investigaciones.

LATOUCHE, S. (1993), El planeta de los naufragos, Madrid, Acento Editorial.

MARCOS, R. y J. ROJO (1991), "Trabajadores extranjeros en España", Revista de Economía y Sociología del Trabajo, $\mathrm{n}^{\circ}$ 11, pp. 8-17.

OYO, P. (1984), Essai sur l'adaptation de travailleurs sénégalais immigrés en région parisienne (Thèse d'Etat), París, Université René Descartes, 222 páginas.

SALEM, G. (1984), "Les marchands ambulants et le système commercial sénégalais en France", Etudes Méditerranéennes, Fasc. 7.

SCHMIDT, O. (1994), Islam, solidarietá e lavoro. I muridi senegalesi in Italia, Fondazione Giovanni Agnelli, Torino.

SUÁREZ, L. (1996), "Estrategias de pertenencia y marcos de exclusión: colectivos sociales y estados en un mundo transnacional", en A. Kaplan (Coord.). Procesos migratorios y relaciones interétnicas, VII Congreso de Antropología Social, Zaragoza, pp. 25-35.

TALL, M.S. (1994), "Les investissements immobiliers à Dakar des émigrants sénégalais", Revue Européenne des Migrations Internationales, vol. 10, $\mathrm{n}^{\circ}$ 3, pp. 137-151.

TRIAUD, J.L. (1997), “África occidental y central”, en G. Veinstein y A. Popovic (eds.), Las sendas de Allah, Barcelona, Edicions Bellaterra, pp. 513-525.

VEINSTEIN, G. y A. POPOVIC (1997), Las sendas de Allah, Barcelona, Edicions Bellaterra.

WERNER, J.F. (1993), Marges, sexes et drogues à Dakar, París, Karthala. 